\title{
AN EXPLORATORY STUDY OF THE LINK BETWEEN STRATEGIC TYPES AND QUALITY IMPLEMENTATION
}

\author{
Terry L. Obert \\ Barbara A. Spencer \\ Mississippi State University \\ Mississippi State, MS
}

\begin{abstract}
This paper explores the relationship between strategy and quality. By drawing on contingency theory and the resource-based view of strategy, we demonstrate conceptual linkages among the two concepts. Then, based on these views, we hypothesize that the use of recognized quality management practices will vary across strategy types. Results of our empirical analysis show clear support for this hypothesis. In other words, there is no "one best way" to implement quality management in organizations.
\end{abstract}

\section{Introduction}

The strategic implications of quality and quality management practices are gaining recognition. Many organizations have found that quality management can enhance their ability to compete in the marketplace (Anderson, Rungtusanatham, and Schroeder 1994). As a result, managers often include practices such as quality planning and continuous quality improvement as part of their strategy formulation process (Pfau 1989).

According to Dean and Bowen (1994), some quality advocates even suggest that quality management should replace strategy. The argument is that continuous quality improvement is all that is needed to create satisfied customers. Dean and Bowen are wary of this view, however, pointing out that high quality by itself may not insure competitive success. Even if customer needs are accurately identified, and organizational processes enhanced, an advantage created in the marketplace will not be sustainable unless the resulting product or service attributes are unique, valuable, and difficult to imitate (Barney 1991). A sound strategy, therefore, both complements and directs quality efforts by ensuring that customer needs are served in ways that competitors cannot duplicate.

Hofer and Schendel (1978) define strategy as the match an organization makes between its internal resources and skills and the opportunities and risks created by its external environment. Based on this definition, it seems clear that quality management practices can support strategy by improving skills and 
developing resources that allow the firm to take advantage of opportunities and avoid risks. Moreover, as the quality of processes and outputs improves in the long run, new opportunities and eventually new strategies are likely to emerge.

It follows that a link should exist between strategy and quality management practices in organizations. In other words, companies pursuing different strategies should emphasize different quality management practices. Firms stressing innovation, for example, are likely to implement different quality practices than those emphasizing efficiency and low cost. Moreover, some strategies may require greater attention to quality overall than do others. In other words, there is no reason to believe that quality management is appropriate for every organization, or that it will look the same for every organization.

The purpose of this paper, therefore, is to investigate the relationship between strategy and quality management practices. It must be noted that this is a study of quality improvement processes, not quality output content. We define quality management practices as those specific activities and techniques that managers implement to improve the way things are done throughout the organization. Examples range from training employees to building supplier relationships.

Specifically, we hypothesize that the use of specific quality management practices will vary across strategy types. Because our data were collected at one point in time, we did not attempt to address causality issues here. We cannot say for sure whether strategy dictates selection of quality methods or whether quality practices influence selection of strategy. Our aim in this study is only to link the two constructs. Our underlying assumption, however, is that quality practices both support the implementation of a given strategy and help shape the choice of new strategy as follows:

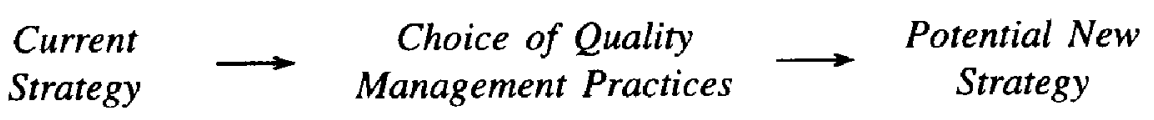

\section{The Strategy-Quality Connection}

The "Best Practices Report" prepared by the American Quality Foundation in cooperation with Ernst \& Young noted that "part of the current skepticism about the quality movement stems from its underlying premise that the same set of management practices can be effective for all organizations" (1992: 7). According to this report, it is this reliance on supposedly "universally beneficial" practices which helps to explain the mixed results gained by many organizations in implementing total quality management. In other words, the "one best way" model does not work any better for quality than it has for other management concepts throughout history. 
Laza and Wheaton (1990) adopt this theme when they note that a common error in implementing quality programs is the failure to recognize that every company, and every environment, is different. They recommend that specific quality practices be matched to the organizational context, or more specifically, to strategy.

Chorn (1991) also suggests that quality management techniques, like other implementation procedures, are contingent on strategy. He contends that total quality management methods should be very useful for strategies emphasizing incremental or evolutionary refinements of organizational products and processes but less applicable to fast-moving organizations whose strategies require risk-taking, creativity, or quantum changes in short periods of time.

Similarly, Krishnan, Shani, Grant, and Baer (1993) state that quality management programs are likely to be most effective when a company in a stable strategic position wishes to enhance its competitive position through long term improvements in product performance and customer satisfaction. They predict that quality programs will be less beneficial for companies whose strategies involve radical restructuring or competitive repositioning.

In general, this work reflects a contingency view in which quality management techniques support the chosen strategy. A change in strategy calls for a change in the quality practices utilized and perhaps even in the degree of emphasis placed on quality management throughout the organization.

A somewhat different view of the strategy/quality relationship can be drawn from the resource-based theory of competitive advantage. Grant (1991) argues that an organization's resources and capabilities serve as the foundation for its strategy. Resources are basic inputs to the production process ranging from employee skills to brand names. A capability is the capacity to perform some task or activity. Capabilities are built from resources and yield competitive advantage. Strategies, in turn, should be built around competitive advantage. Belohlav (1993a, 1993b) explains how high quality influences competitive position which, in turn, opens a new range of strategic options to the company. By implementing quality practices, a firm may develop new skills or capabilities which lead to the development of new strategies. Prahalad and Hamel (1990) use the term "core competencies" to describe these central, strategic capabilities. By developing unique capabilities over time, a firm gains the capacity to adopt new and different strategies.

Spitzer (1993) also reflects this view when he describes TQM as the only source of competitive advantage. Drawing on work by Feeny and Ives (1990), Spitzer shows how quality management can help a company build generic lead time, leverage competitive asymmetries, and create preemption potential, all of which are crucial to sustainable competitive advantage. The implication is that quality management can create these sources of competitive advantage and that companies should build strategies around them (Spitzer 1993: 61).

In summary, both contingency theory and the resource-based view offer explanations for a linkage between strategy and quality in organizations. In the 
former case, strategy dictates particular quality practices and in the latter, improved quality processes and outputs enable new strategic choices. Combining the two approaches suggests that the relationship between strategy and quality management may be a reciprocal one. That is, at time A, the choice of appropriate quality management techniques may be influenced by company strategy. At time B, however, the improvement of products and processes may generate new capabilities that allow modification of the strategy in ways that yield greater performance results. Whatever the causality, it seems clear that we can expect to find a link between strategy and quality management techniques. Thus we hypothesize that at a given point in time, organizations following different competitive strategies will utilize different combinations of quality management methods.

\section{Operationalization of Concepts}

\section{Method}

Strategy Types. Miles and Snow's (1978) well-known strategic typology identifies four primary strategy types: prospectors, defenders, analyzers, and reactors. Prospectors are entrepreneurial firms whose managers actively seek new opportunities in the marketplace, are willing to take risks and develop new innovative businesses, and who don't mind trading off efficiency for growth. Defenders, in contrast, stress efficiency with tightly organized firms focused on a narrow market niche. They emphasize the engineering aspects of production and pay close attention to the bottom line. Because defenders abhor risk, they tend to lag behind industry competitors in innovations seeking only proven opportunities in their area of expertise.

Analyzers blend elements of both prospector and defender strategies and so are able to focus on efficiency and productivity when the market is stable or on scanning and innovation when the market is turbulent. These organizations balance risks and returns by following other firms (usually prospectors) into new markets and improving on their technological advances. Although they sometimes move from stable markets to dynamic ones, they do so with foresight. Reactors, on the other hand, have no clear strategic orientation. As their name implies, they tend to react to environmental trends and as a result, often find themselves in crisis. Their behaviors are unstable and their decisions are oriented toward the short versus the long term.

Our choice of this typology to operationalize the strategic context of organizations was based on its assumption that relatively enduring links exist among strategy, structure, and process variables. Prior research (cf., Conant, Mokwa and Varadarajan 1990; Snow and Hrebiniak 1980; Smith, Guthrie and Chen 1986) has linked the first three strategy types with consistent responses to environmental challenges and hence good performance. Reactors, however, respond uncertainly or inappropriately and are generally linked with poor performance.

To measure strategic type, we followed procedures prescribed by Conant, Mokwa and Varadarajan (1990). These authors developed a multi-item scale 
based on the strategic dimensions associated with the Miles and Snow (1978) typology. This instrument, which identifies respondents as prospectors, defenders, analyzers, or reactors, is contained in Appendix A. These questions were developed using a panel of organization theory and strategy researchers. Questions and response options were revised iteratively until the entire panel agreed that each question and response option accurately measured the intended strategic type.

Conant et al. (1990) field-tested the instrument along with Snow and Hrebiniak's (1980) paragraph approach to operationalizing the Miles and Snow (1978) strategic typology. This dual use allowed them to compare the classifications made by each instrument. They followed a test-retest procedure on 102 of their respondents and found that the percentage of organizations classified similarly during the initial test and then during the retest for the paragraph approach and the multi-item instrument was 0.75 and 0.74 , respectively. The reliability coefficients for the multi-item scale ranged from 0.56 to 0.82 , with a mean reliability of 0.69. Although Conant et al. (1990) acknowledged that their multi-item measure is still in need of additional refinement, the results of the initial field test of the instrument are deemed strong enough to warrant its use in this study.

Quality Management Practices: Quality as an output is distinct from those processes used internally to create it. As noted earlier, this research emphasizes quality management practices such as employee training and relationships with suppliers.

Saraph, Benson and Schroeder (1989) identified eight critical factors of quality management at the business unit level. In this study, we used six of these dimensions to measure the degree of quality implementation within a company. These included: role of top management and quality policy, quality training, product/service designs, supplier quality management, quality data and reporting, and employee relations. The other two dimensions, role of the quality department and process management/operating procedures, were not used both to reduce the length of the questionnaire and to make it more applicable to service as well as manufacturing companies. For each question, respondents were asked to indicate the extent or degree of current practice within their organization using the scale: Very low (1), Low (2), Medium (3), High (4), Very High (5), and Unable to Judge (6). Appendix B provides a list of the questions asked and the dimensions those questions represented.

Eleven demographical questions were also asked, determined in part by the work of Benson, Saraph, and Schroeder (1991) who found that the size of the company responding, the type of the company, and the position in the company held by the respondent all influence quality management. Questions about downsizing, annual turnover, and whether or not the company had experienced any change in market share over the last two years were asked and are shown in Appendix C. 


\section{Data Collection and Analysis}

A five page, 73-item survey was sent to 2084 firms randomly selected from the COMPUSTAT data base. Selections were made from companies traded on the New York Stock Exchange, the American Stock Exchange, Overthe-Counter, the Regional Stock Exchange, and the Non-NASDAQ using a randomization algorithm. No attempt was made to limit the sample by company size, type (i.e., service or manufacturing), or location. The sample contained at least one company from all fifty states except Alaska and 165 companies located outside the U.S.

Self-reported measures of strategic type, quality management implementation, and company demographics were collected from each company representative. Responses were first categorized by strategy type based on a majority-rule decision. Following Conant et al. (1990), ties between defender, prospector and/or analyzer responses were resolved by designating the respondent as an analyzer, which is considered a hybrid of the other two. Ties with reactor responses resulted in the respondent being categorized as a reactor since they are typically inconsistent in their responses and could exhibit some tendencies of all four types.

Items from the quality management section were grouped into scales representing six of Saraph et al.'s (1989) quality dimensions. Cronbach's (1951) alpha was calculated for each dimension, and all values were .80 or higher indicating a high degree of internal consistency in this application of the instrument. Mean scores generated for each dimension represented the extent of each separate quality management practice.

In order to investigate the proposition that perceptions of the current practice of quality management in the company will differ by strategic type, analysis of variance and mean comparisons were performed on each quality dimension by strategic type, with and without controlling for company type, size, and position in the company held by the respondent.

\section{Results}

Responses were received from 64 companies, with an additional 27 questionnaires returned as nondeliverable. Because the questionnaire was lengthy, the low response rate was not unexpected. We did not test for nonresponse bias, but we did note that the companies from which respondents returned surveys were small to mid-sized and were split between manufacturing and service. They represented almost every state and three foreign countries. Finally, they had predominantly experienced an increase in market share and employed quality professionals as a consulting resource.

When the responses were scored by strategic type, one questionnaire could not be used which reduced the sample size to 63 . Additionally, when the 51 questions on quality implementation were reviewed, one respondent answered 
too few of the questions for the survey to be used, resulting in a final sample size of 62 . Of these, 21 were categorized as prospectors, 20 were categorized as analyzers, 11 were categorized as reactors, and 10 were categorized as defenders.

To get an initial view of the extent of quality management practiced by the sample firms, the 51 questions in the quality implementation survey were averaged for each respondent and then an overall average was calculated for each strategic type. These results are in Table 1, from which it can be seen that analyzers perceive the current extent of quality implementation within their company to be moderate to high, prospectors and defenders perceive it to be moderate, and reactors perceive it as low to moderate. Since reactors are generally linked with poor performance and an orientation for short-term, stopgap solutions, it is not surprising that these companies have less well-developed quality policies in place than the others.

Table 1

Averages Among Strategic Types for Responses to all 51 Questions on the Quality Implementation Survey

\begin{tabular}{lllc}
\hline Strategic Type & N & Mean & Standard Deviation \\
\hline Analyzer & 20 & 3.49 & .51 \\
Prospector & 21 & 3.20 & .47 \\
Defender & 10 & 3.02 & .53 \\
Reactor & 11 & 2.82 & .47 \\
\hline
\end{tabular}

Degree of Implementation in Your Company:

Very Low (1), Low (2), Medium (3), High (4), Very High (5)

To examine whether or not the four strategic types differed in their responses to each separate quality dimension, an analysis of variance was performed using a randomized block design where the questions comprising a dimension were the blocks. Company size, type of company, and position held in the company by the respondent were not part of this model which only examined whether or not there were significant differences among strategic types for each dimension. The $F$ and $p$-values for these analyses are given in Table 2 and support the premise of significant differences among strategic types across all six critical dimensions of quality management.

Table 3 displays the $\mathrm{F}$ and p-values for the model with company size, type of company, and position of the respondent as well as strategic type. For this model, only strategic type and type of company had a significant effect on the average quality score which was obtained by averaging responses across all 51 questions without regard to the six separate quality dimensions. 
Table 2

Significance of Differences Among the Strategic Types for the Six Dimensions on the Quality Implementation Survey

\begin{tabular}{lcc}
\hline Quality Dimension & F Value & p-value \\
\hline 1. Role of Top Management & 16.71 & .0001 \\
2. Training & 29.94 & .0001 \\
3. Product/Service Design & 12.86 & .0002 \\
4. Supplier Quality Management & 10.81 & .0002 \\
5. Quality Data and Reporting & 12.89 & .0001 \\
6. Employee Relations & 12.94 & .0001 \\
\hline
\end{tabular}

Table 3

Effects of Strategic Type, Type of Company, Size of the Company, and Position Held by Respondent on Average Quality Score

\begin{tabular}{lcc}
\hline Source & F Value & p-value \\
\hline Strategic Type & 2.73 & $.0531^{*}$ \\
Type of Company & 5.17 & $.0090^{*}$ \\
Size of the Company & 0.04 & .9899 \\
Position of the Respondent & 1.92 & .1713 \\
\hline
\end{tabular}

* Significant at .10 or less

The results in Table 3 suggest that a model using strategic type as the independent variable and type of company as a covariate should be chosen to investigate differences in responses for the four strategic types for each of the six quality dimensions. Subsequently, significant differences among strategic types were obtained and least squares means were used to conduct pairwise comparisons tests. These results are displayed in Table 4 .

Table 4

Differences Among Strategic Types Controlling for Type of Company

\begin{tabular}{lcccc}
\hline & Analyzer & Prospector & Defender & Reactor \\
\hline Role of Top Management & $\mathbf{a}$ & $\mathbf{b}$ & $\mathbf{b}$ & $\mathbf{b}$ \\
Training & $\mathbf{a}$ & $\mathbf{b}$ & $\mathbf{c}$ & $\mathbf{b , c}$ \\
Product/Service Design & $\mathbf{a}$ & $\mathbf{b , c}$ & $\mathbf{a , b}$ & $\mathbf{c}$ \\
Supplier Quality Management & $\mathbf{a}$ & $\mathbf{a}$ & $\mathbf{b}$ & $\mathbf{b}$ \\
Quality Data and Reporting & $\mathbf{a}$ & $\mathbf{a}$ & $\mathbf{a , b}$ & $\mathbf{b}$ \\
Employee Relations & $\mathbf{a , b}$ & $\mathbf{b}$ & $\mathbf{c}$ & $\mathbf{a}$ \\
\hline
\end{tabular}

Strategic types with the same letter are not statistically significantly different at the .05 level 
For the dimensions of training and the role of top management, analyzers have a significantly different view than the others. The analyzers reported a higher level of acceptance of responsibility for quality and support for quality performance by the top management of their company. They also perceive the level of quality-related training as being higher in their company than the other respondents did. These results support the findings of Miles and Snow (1978) who characterized analyzers as prone to forming planning staffs, and making comprehensive plans. Perhaps respondents from analyzer firms view quality-related training as the first step toward employee quality performance.

All four strategic types had similar views on product/service design. In terms of supplier quality management, analyzers and prospectors are more likely to involve the supplier in their product development process and select a supplier on the basis of quality than reactors and defenders are.

All four strategic types perceive the degree of the collection and analysis/use of quality data as a tool for managing product quality in their companies as moderate at best. This finding was consistent with views expressed by Baldridge examiner George Easton who noted that quality data is generally not well organized to support quality management in U.S. firms (Easton, 1993).

With regard to the role employees are expected to play in quality management, reactors show the most empowerment of employees while defenders seem the least inclined to pass the quality responsibility directly to the employees. This lack of delegation is quite consistent with the mechanistic, highly centralized management style typically associated with defender organizations. It seems from this data that our defenders still believe that quality can be "managed" into a product.

\section{Conclusions}

The majority of the respondents (78\%) were CEOs, Directors, Presidents, or Vice Presidents of the company. It would seem a reasonable assumption that these respondents have a strong hand in the policies implemented by the company. Therefore, based on the results presented here, companies guided by analyzers are most likely to implement quality policies and practices while reactors are the least likely to implement them. Generally prospectors and defenders will fall somewhere in the middle, although they will more often resemble analyzers than reactors.

These results were quite consistent with our understanding of activities and behaviors typically associated with Miles and Snow's (1978) strategic types. The analyzers in this sample, for example, reported the most emphasis on quality management overall. In an attempt to balance stability and change, this strategy type tends to emphasize planning, coordinating and learning: they move into new markets only after their viability has been demonstrated; they use mechanisms such as cross functional teams as a normal part of daily op- 
erations. Hence it makes sense that their managers are willing to support the up-front preparation and training necessary to put quality programs in place. As Spitzer (1993) points out, it takes a long time to bring quality initiatives on line, and analyzers, with their emphasis on both effectiveness and efficiency, may have the foresight and capability to see it through.

Defenders, on the other hand, are motivated to keep costs down. Training costs money - as a result, they invest in less training than any other strategy type. In addition, they are highly centralized. As a result, we saw little use of employee empowerment among the defenders in our sample.

Our finding that prospectors did not place a great deal of emphasis on quality practices also has support in the literature. Both Chorn (1991) and Krishnan et al. (1993) posited that quality practices would be inconsistent with strategies based on rapid change and repositioning.

As a whole, these results clearly support the central hypothesis of this research; that is, in our sample at least, there is a significant relationship between strategy type and quality management approach. This relationship manifested itself despite our small sample size and the low power of our statistical tests. Certainly, we can make no comments concerning the generalizability of our findings, but they suggest intriguing possibilities for future study.

The causal nature of this linkage remains open to interpretation. The typology we used here assumes organizations to be characterized by enduring patterns of adaptive behavior. The introduction of quality management processes could represent a reinforcement of the pattern, or could lead to the initiation of a new pattern. Strategic contingency theory would suggest the former; the resource based approach appears to assume the opposite. Both theories support the alignment between strategy and quality management processes at a given point in time.

Future research should use a longitudinal approach to examine whether quality management precedes or follows strategic change. In addition, the effects of other changes should be studied. For example, what happens to the alignment between strategy and quality when companies experience growth and decline? How does this relationship affect performance?

Dean and Bowen (1994) suggest that both conceptual and empirical work is needed to sort out differences among the various total quality and management theory positions on the role of quality and strategy. This paper has attempted to make preliminary progress on both fronts, first by tracing the linkages between quality and strategy based on the strategy literature, and second, by examining data from a sample of diverse organizations. Given our results, we suggest that the challenge to researchers is to continue this research stream in new contexts and with different methods. The challenge to practitioners is to ensure that their choice of quality management practices both supports current strategic efforts and enhances future strategic changes.

At a minimum, practitioners should look at pre-packaged quality programs and standardized applications of quality techniques with skepticism. There is 
no "one best way" to implement quality management. We contend that a well thought out strategy must drive the development and application of quality practices throughout the organization. Managers may want to begin by improving processes and implementing practices that enhance the firm's ability to satisfy customer needs, while also protecting it from imitation by competitors. Over time, as new skills are learned and new capabilities developed, new opportunities may emerge and new strategies may be enabled.

\section{References}

Anderson, J.C., M. Rungtusanatham, and R.G. Shroeder. "A Theory of Quality Management Underlying the Deming Management Method." Academy of Management Joumal 19(3) (1994): 446-471.

Barney, J.B. "Firm Resources and Sustained Competitive Advantage." Journal of Management 17(1) (1991): 99-120.

Belohlav, J.A. "Developing the Quality Organization." Quality Press 26(10) (1993a): 119-122.

Belohlav, J.A. "Quality, Strategy and Competitiveness." California Management Review 35(3) (1993b): 55-67.

Benson, G.P., J.V. Saraph, and R.G. Schroeder. "The Effects of Organizational Context on Quality Management: An Empirical Investigation." Management Science 37(9), (September 1991): 1107-1124.

Chorn, N.H. "Total Quality Management: Panacea or Pitfall?" International Journal of Physical Distribution and Logistics Management 21(8) (1991): 31-35.

Conant, J.S., M.P. Mokwa, and R. Varadarajan. "Strategic Types, Distinctive Marketing Competencies and Organizational Performance: A Multiple Measures-Based Study." Strategic Management Journal 11(5), (September 1990): 365-383.

Dean, J.W., Jr. and D.E. Bowen. "Management Theory and Total Quality: Improving Research and Practice Through Theory Development." Academy of Management Journal 19(3) (1994): 392-418.

Easton, G.S. "The 1993 State of U.S. Total Quality Management: A Baldridge Examiner's Perspective." California Management Review 34(3) (1993): 32-54.

Ernst \& Young and the American Quality Foundation. Best_Practices Report. New York: Ernst \& Young, 1992.

Feeny, D.F. and B. Ives. "In Search Of Sustainability: Reaping Long-Term Advantage from Investments in Information Technology." Journal of Management and Information Systems 7(1) (1990). 
Grant, R.M. "The Resource-Based Theory of Competitive Advantage." California Management Review (Spring 1991): 114-135.

Hofer, C.W. and D. Schendel. Strategy Formulation:Analytic Concepts. St. Paul: West, 1978, pp. 12.

Krishnan, R., A.B. Shani, R.M. Grant, and R. Baer. "In Search of Quality Improvement: Problems of Design and Implementation." Academy of Management Executive 7(4) (1993): 7- 20.

Laza, R.W. and P.L. Wheaton. "Recognizing the Pitfalls of Total Quality Management." Public Utilities Fortnightly (April 1990): 17-21.

Miles, R. and C. Snow. Organizational Strategy, Structure and Process. New York: McGraw-Hill, 1978.

Pfau, L.D. "Total Quality Management Gives Companies A Way to Enhance Position in Global Marketplace." Industrial Engineering 21(4), (April 1989): 17-21.

Prahalad, C.K. and G. Hamel. "The Core Competence of the Corporation." The Harvard Business Review (May-June 1990): 79-91.

Saraph, J.V., G.P. Benson, and R.G. Schroeder. "An Instrument for Measuring the Critical Factors of Quality Management." Decision Sciences 20(4), (Fall 1989): 810-829.

Smith, K.G., J.P. Guthrie, and M. Chen. "Miles and Snow's Typology of Strategy, Organizational Size and Organizational Performance." Academy of Management Review 5(4), (October 1986): 527-538.

Snow, C.C. and L.G. Hrebiniak. "Strategy, Distinctive Competence, and Organizational Performance." Administrative Science Quarterly 25(2), (June 1980): 317-336.

Spitzer, R.D. "TQM: The Only Source of Sustainable Competitive Advantage." Quality Progress (June 1993); pp. 59-64. 


\section{Appendix A Strategic Type Instrument}

Directions: Please read the following eleven questions carefully. For each one, select the answer that best describes your organization and circle the letter for that answer.

1. In comparison to our competitors, the products/services which we provide to our customers are best characterized as:

a. Products/services which are more innovative, continually changing and broader in nature throughout the organization and marketplace. (P)

b. Products/services which are fairly stable in certain units/departments and markets while innovative in other units/departments and markets. (A)

c. Products/services which are well focused, relatively stable and consistently defined throughout the organization and marketplace. (D)

d. Products/services which are in a state of transition, and largely based on responding to opportunities or threats from the marketplace or environment. (R)

2. In contrast to our competitors, our organization has an image in the marketplace as a company which:

a. Offers fewer, selective products/services which are high in quality. (D)

b. Adopts new ideas and innovations, but only after careful analysis. (A)

c. Reacts to opportunities or threats in the marketplace to maintain or enhance our position. (R)

d. Has a reputation for being innovative and creative. (P)

3. The amount of time my company spends on monitoring changes and trends in the marketplace can best be described as:

a. Lengthy: We are continuously monitoring the marketplace. (P)

b. Minimal: We really don't spend much time monitoring the marketplace. (D)

c. Average: We spend a reasonable amount of time monitoring the marketplace. (A)

d. Sporadic: We sometimes spend a great deal of time and at other times spend little time monitoring the marketplace. (R)

4. In comparison to our competitors, the increases or losses in demand which we have experienced are due most probably to:

a. Our practice of concentrating on more fully developing those markets which we currently serve. (D)

b. Our practice of responding to the pressures of the marketplace by taking few risks. (R)

c. Our practice of aggressively entering into new markets with new types of product/service offerings. (P)

d. Our practice of assertively penetrating more deeply into markets we currently serve, while adopting new products/services only after a very careful review of their potential. (A) 
5. One of the most important goals in my company, in comparison to our competitors, is our dedication and commitment to:

a. Keep costs under control. (D)

b. Analyze our costs and revenues carefully, to keep costs under control and to selectively generate new products/services or enter new markets. (A)

c. Insure that the people, resources and equipment required to develop new products/services and new markets are available and accessible. (P)

d. Make sure that we guard against critical threats by taking whatever action is necessary. (R)

6. In contrast to our competitors, the competencies (skills) which our managerial employees possess can best be characterized as:

a. Analytical: Their skills enable them to both identify trends and then develop new product/service offerings or markets. (A)

b. Specialized: Their skills are concentrated into one, or a few, specific areas. (D)

c. Broad and entrepreneurial: Their skills are diverse, flexible, and enable change to be created. (P)

d. Fluid: Their skills are related to the near-term demands of the marketplace. (R)

7. The one thing that protects our organization from our competitors is that we:

a. Are able to carefully analyze emerging trend and adopt only those which have proven potential. (A)

b. Are able to do a limited number of things exceptionally well. (D)

c. Are able to respond to trends even though they may possess only moderate potential as they arise. (R)

d. Are able to consistently develop new products/services and new markets. (P)

8. More so than many of our competitors, our management staff tends to concentrate on:

a. Maintaining a secure financial position through cost and quality control measures. (D)

b. Analyzing opportunities in the marketplace and selecting only those opportunities with proven potential, while protecting a secure financial position. (A)

c. Activities or business functions which most need attention given the opportunities or problems we currently confront. (R)

d. Developing new products/services and expanding into new markets or market segments. (P)

9. In contrast to many of our competitors, our organization prepares for the future by:

a. Identifying the best possible solutions to those problems or challenges which require immediate attention. ( $R$ )

b. Identifying trends and opportunities in the marketplace which can result in the creation of product/service offerings which are new to the industry or which reach new markets. (P) 
c. Identifying those problems which, if solved, will maintain and then improve our current product/service offerings and market position. (D)

d. Identifying those trends in the industry which our competitors have proven possess long-term potential while also solving problems related to our current product/service offerings and our current customers' needs. (A)

10. In comparison to our competitors, the structure of our organization is:

a. Functional in nature (i.e., organized by department-marketing, accounting, personnel, etc.). (D)

b. Product/service or market oriented (i.e., individual units/departments have marketing or accounting responsibilities). (P)

c. Primarily functional (departmental) in nature; however, a product/service or market oriented structure does exist in newer or larger product/service offering areas. (A)

d. Continually changing to enable us to meet opportunities and solve problems as they arise. $(\mathbf{R})$

11. Unlike many other similar companies, the procedures our organization uses to evaluate our performance are best described as:

a. Decentralized and participatory encouraging many organizational members to be involved. (P)

b. Heavily oriented toward those reporting requirements which demand immediate attention. ( $R$ )

c. Highly centralized and primarily the responsibility of senior management. (D)

d. Centralized in more established product/service areas and more participatory in newer product/service areas. (A)

\section{Appendix B \\ Dimensions Measured and Questions Asked By The Quality Implementation Survey}

Degree of Implementation Within Your Company: Very Low (1), Low (2), Medium (3), High (4), Very High (5), Unable to Judge (6)

\section{Dimension 1: Role of Top Management and Quality Policy}

1. Extent to which the top executive assumes responsibility for quality performance.

2. Acceptance of responsibility for quality by major department heads.

3. Degree to which top management (top management executive and major department heads) is evaluated for quality performance.

4. Extent to which the top management supports long-term quality improvement process.

5. Degree of participation by major department heads in the quality improvement process.

6. Extent to which the top management has objectives for quality performance.

7. Specificity of quality goals within the company.

8. Comprehensiveness of the goal-setting process for quality in the company.

9. Extent to which quality goals and policy are understood within the company. 
10. Importance attached to quality by the top management in relation to cost and schedule objectives.

11. Amount of review of quality issues in top management meetings.

12. Degree to which the top management considers quality improvement as a way to increase profits.

13. Degree of comprehensiveness of the quality plan within the company.

Dimension 2: Training

14. Specific work-skills training (technical and vocational) given to hourly employees throughout the company.

15. Quality-related training given to hourly employees throughout the company.

16. Quality-related training given to managers and supervisors throughout the company.

17. Training in the "total quality concept" (i.e., philosophy of company-wide responsibility for quality) throughout the company.

18. Training in the basic statistical techniques (such as histograms and control charts) in the company as a whole.

19. Training in advanced statistical techniques (such as design of experiments and regression analysis) in the company as a whole.

20. Commitment of the top management to employee training.

21. Availability of resources for employee training in the company.

Dimension 3: Product/Service Design

22. Thoroughness of the new product/service reviews before the product/service is produced and marketed.

23. Coordination among affected departments in the product/service development process.

24. Quality of new products/services emphasized in relation to cost or schedule objectives.

25. Clarity of product/service specifications and procedures.

26. Extent to which implementation/producibility is considered in the product/service design process.

27. Quality emphasis by sales, customer service, marketing, and PR personnel.

Dimension 4: Supplier Quality Management (Supplier of Goods and/or Services)

28. Extent to which suppliers are selected based on quality rather than price or schedule.

29. Thoroughness of the supplier rating system.

30. Reliance on reasonably few dependable suppliers.

31. Amount of education of supplier by company.

32. Technical assistance provided to the suppliers.

33. Involvement of the supplier in the product development process.

34. Extent to which longer-term relationships are offered to suppliers.

35. Clarity of specifications provided to suppliers.

Dimension 5: Quality Data and Reporting

36. Availability of cost of quality data in the company.

37. Availability of quality data (error rates, defect rates, scrap, etc.). 
38. Timeliness of the quality data.

39. Extent to which quality data are available to hourly employees.

40. Extent to which quality data are available to managers and supervisors.

41. Extent to which quality data are used to evaluate supervisor and managerial performance.

42. Extent to which quality data, control charts, etc., are displayed at employee work stations.

Dimension 6: Employee Relations

43. Extent to which quality circle or employee involvement type programs are implemented in the company.

44. Effectiveness of quality circle or employee involvement type programs in the company.

45. Extent to which employees are held responsible for error-free output.

46. Amount of feedback provided to employees on their quality performance.

47. Degree of participation in quality decisions by hourly/nonsupervisory employees.

48. Extent to which quality awareness building among employees is ongoing.

49. Extent to which employees are recognized for superior quality performance.

50. Effectiveness of supervisors in solving problems/issues.

\section{Appendix C \\ Demographics}

Question

Percent

1. Company Size: Under 1000 employees

42.2

1000-5000 employees

5000-10,000 employees

1.6

More than 10,000 employees

2. Company Type: Service

Manufacturing

Other

3. Employees are Unionized: Yes

68.7

No

73.4

4. Utilized Quality Professionals as Consultants: Yes

5. Applied for a Quality Award: Yes

No

6. Marketshare May 91-May 93: Increased 
7. Reduction in Force May 91-May 93: Yes 34.4

No $\quad 65.6$

8. Position Held by Respondent: CEO 23.0

Directors 25.0

President/VP $\quad 30.0$

Others 22.0

9. Average percentage Annual Turnover: Hourly 6.2

10. Average percentage Annual Tumover: Salaried 6.0

11. States Represented: AR, AZ, CA, CO, CT, FL, GA, IA, ID, IO, IL, IN, MA, MI, MN, MS, NC, NH, NJ, NV, NY, OH, OR, PA, SC, SD, TN, TX, WA, WI 